\title{
Para-occupational exposure to pesticides, PON1 polymorphisms and hypothyroxinemia during the first half of pregnancy in women living in a Mexican floricultural area
}

Luisa Torres-Sánchez , Ricardo Gamboa², Susana Bassol-Mayagoitia ${ }^{3}$, Claudia Huesca-Gómez², Martha Patricia Nava ${ }^{3}$, Jennifer Illian Vázquez-Potisek ${ }^{3}$, Leticia Yáñez-Estrada ${ }^{4}$, Rebeca Mejía-Saucedo ${ }^{4}$ and Julia Blanco-Muñoz ${ }^{1 *}$ (D)

\begin{abstract}
Background: Adequate maternal thyroxine (T4) concentrations during the first half of pregnancy are fundamental to the embryo's or fetus' neural development. Organophosphate pesticides (OP) can act as thyroid disruptors and genetic polymorphisms for paraoxonase 1 (PON1), an enzyme that detoxifies OP, could be involved in individual's susceptibility to them. We assessed the association between para-occupational exposure to pesticides, including $\mathrm{OP}$, during pregnancy and maternal hypothyroxinemia, as well as the potential genetic susceptibility conferred by PON1 polymorphisms.

Methods: We analyzed information from 381 healthy pregnant women ( $<17$ gestational weeks), who lived in a floricultural region of Mexico where pesticides, including OP, are routinely used. Women who were para-occupationally exposed to pesticides were those whose partner had an occupation involving contact with these products. ThyroidStimulating Hormone (TSH) and free T4 concentrations were determined using ELISA, and hypothyroxinemia was defined as free T4 concentrations $<0.76 \mathrm{ng} / \mathrm{dL}$. PON1192QR, PON155LM and PON1-108CT polymorphisms were determined through Polymerase Chain Reaction (PCR). The association between para-occupational exposure and genetic polymorphisms and hypothyroxinemia was estimated using logistic regression models.

Results: One hundred and sixty two women (42.52\%) were classified as para-occupationally exposed to pesticides. Hypothyroxinemia prevalence was $54 \%$, and it was not significantly associated with pesticide para-occupational exposure (OR: 1.21 95\% Cl 0.75-1.94). Independently of para-occupational exposure, the likelihood of hypothyroxinemia was higher among women who were carriers of PON155MM than in those with PON155LL genotype (OR MM vs LL: 3.03; 95\%Cl 1.62, 5.70). PON1192 RR (OR RR vs oQ: 1.72; 95\%Cl 0.93, 3.17) and PON1-108TT (OR $\pi$ vs CC: 1.60; 95\%Cl 0.90, 2.70) genotypes were marginally associated with hypothyroxinemia. No significant interaction was observed between pesticides para-occupational exposure and PON1 polymorphisms.

Conclusions: These results suggest that PON1 polymorphisms could affect thyroid function during pregnancy in women living in areas where pesticides, including OP, are routinely used. Low exposure variability in this population, could be a possible explanation for the lack of association between para-occupational exposure and thyroid function.
\end{abstract}

Keywords: PON1 polymorphisms, Thyroid hormones, Pregnancy, Pesticides

\footnotetext{
* Correspondence: jblanco@insp.mx

${ }^{1}$ Instituto Nacional de Salud Pública, Av. Universidad 655, Col. Sta. María

Ahuacatitlán, 62100 Cuernavaca, Morelos, CP, Mexico

Full list of author information is available at the end of the article
}

(c) The Author(s). 2019 Open Access This article is distributed under the terms of the Creative Commons Attribution 4.0 International License (http://creativecommons.org/licenses/by/4.0/), which permits unrestricted use, distribution, and reproduction in any medium, provided you give appropriate credit to the original author(s) and the source, provide a link to the Creative Commons license, and indicate if changes were made. The Creative Commons Public Domain Dedication waiver (http://creativecommons.org/publicdomain/zero/1.0/) applies to the data made available in this article, unless otherwise stated. 


\section{Introduction}

Thyroid hormones play a fundamental role in cellular metabolism and in nervous system growth and development, especially during the intrauterine period and early childhood. The fetal thyroid gland efficiently produces thyroid hormones at approximately 16-18 weeks of pregnancy, meaning that during the first half of pregnancy the embryo or fetus requires an adequate maternal thyroid function for adequate neuronal migration and differentiation [1]. Thyroxine (T4) can cross the placental barrier and moderate and severe maternal hypothyroxinemia during the first weeks of pregnancy has been associated with infant neurodevelopment alterations [2, 3].

Iodine deficiency and autoimmune disease are the factors most frequently involved in thyroid dysfunction; however, the effect of environmental toxins exposure on thyroid function has become relevant in the last decades [4]. Evidences from the general population [5] and from men of reproductive age $[6,7]$, suggest that exposure to organophosphate pesticides can produce subclinical changes of the thyroid profile. Nevertheless, its importance at a clinical or biological level is not clearly established and few studies have included factors related to genetic susceptibility to these toxins [8].

Paraoxonase 1 (PON1) is an enzyme linked to high density proteins that decreases lipid peroxidation [9] and is also involved in detoxification of some OP pesticides. The gene that codes for PON1 has two common polymorphisms in the coding region. The first is a substitution of methionine for leucine in position $55(55 \mathrm{~L} / \mathrm{M})$, and the second one is a substitution of arginine for glutamine in position $192(192 Q / R)$. There are other polymorphisms in the promoter region, of which the most studied is $-108 \mathrm{C} / \mathrm{T}$. The $T$ allele at position -108 and the $M$ allele in position 55 are associated with plasmatic paraoxonase level decrease [10]; while the $R$ allele in position 192 synthesizes a less efficient paraoxonase enzyme against HDL and LDL oxidation [11]. PON1's detoxifying activity depends on enzyme structure and substrate. Both isoforms resulting from $P O N 1_{192}$ polymorphism have a different hydrolysis rate against some OP substrates: $P O N 1_{192 R}$ metabolizes chlorpyrifos pesticide more efficiently than isoform $P O N 1_{192 Q}$, whereas no difference was observed in diazinon metabolism [12].

A study performed on healthy post-menopausal women with no pesticide exposure found a negative association between $R$ allele of the polymorphism $P O N 1_{192}$ and free T3 levels [13]. Additionally, in male flower workers from a floricultural area of Mexico, our research group found a positive association between urine concentration of dialkylphosphate (DAP) OP metabolites and TSH and total T4 levels and a negative association with total T3 [6], as well as a decrease in the percentage of variation of TSH among carriers of $P O N 1_{192} R R$ genotype [8]. Among pregnant women residing in this area we found a high frequency of hypothyroxinemia (53\%) [14].

Given the importance of maternal thyroid function in adequate fetal development and the scarcity available information on pregnant women, in the present study we estimated the association between para-occupational exposure (exposure of a worker's family to substances carried from the workplace to the home) to pesticides and maternal hypothyroxinemia during the first half of pregnancy, as well as the possible interaction with maternal PON1 polymorphisms (PON1192Q/R, PON155 L/M and PON1-108C/T).

\section{Material and methods}

\section{Study population and data collection instruments}

We assembled a pregnancy cohort study in a floricultural region of the State of Mexico, the main flower producing area in the country, located in central Mexico. The main objective was to evaluate the effect of pesticide exposure during pregnancy, as well as the interaction with PON1 polymorphisms, on the occurrence of adverse reproductive outcomes, with a particular interest in maternal thyroid profile. Details about the selection of the study population have been published previously [14].

Briefly, during the period of July 2013-August 2015, we identified pregnant women who were 15-40 years old, with a gestational age of less than 17 weeks, with no chronic illnesses, and a residence time of at least 1 year in Tenancingo, Zumpahuacán, Tonatico and Villa Guerrero. In these municipalities, the main economic activity is floriculture, and the inhabitants are environmentally, para-occupationally or occupationally exposed to pesticides, mainly those of the OP family: diazinon, methamidophos, omethoate and methyl parathion [15].

Eligible women were identified at health centers of these municipalities when they attended for their first prenatal visit. All participating women signed an informed consent letter; for women under 18 years of age, in addition to their agreement we obtained an informed consent letter from their parents. The study was approved by the Ethics Committee of the National Public Health Institute of Mexico.

Once women were recruited, height and weight were measured and they were asked to complete a questionnaire to collect sociodemographic characteristics, reproductive background, work history, alcohol, tobacco and coffee consumption before and during pregnancy and intake of supplements containing iodine during 3 months prior to becoming pregnant and until the time when they were included in the study. They were also queried regarding the child's father (sociodemographic data, medical history, and occupation). To determine thyroid hormones (TH), PON1192, PON155, and PON1-108 
genotypes, and OP metabolites, a blood and urine sample was obtained under fasting conditions between 8 and 10:30 AM from each woman.

Out of 635 eligible pregnant women, 480 (75.6\%) agreed to participate in the study. The main reason for non-participation was lack of time. This report corresponds to 381 pregnant women who had complete questionnaire information, and whose PON1 polymorphisms and $\mathrm{TH}$ results at the time they entered the study (baseline) were available. No significant differences were observed between these women and the remaining participants with respect to sociodemographic characteristics, number of pregnancies, alcohol and tobacco use, and gestational age at baseline (data not shown).

\section{Thyroid hormones determination}

Serum TSH concentrations and free T4 were determined by Enzyme-Linked ImmunoSorbent Assay (ELISA), using an automated immunoassay system (DRG International, Inc., USA). Reference values for $\mathrm{TH}$ concentrations for pregnant women were assessed according to the information provided in the commercial kits, as follows: a) TSH 0.5 to $5.0 \mathrm{mlU} / \mathrm{L}$ and free T4 0.76 to $2.24 \mathrm{ng} / \mathrm{dL}$.

Intra-assay serum TSH variation coefficients and free T4 were 3.36 to $3.88 \%$ and 3.2 to $10.9 \%$, respectively. Inter-assay variation coefficients were 3.3 to $9.1 \%$ and 7.9 to $10.8 \%$, respectively. Analytical sensitivity for TSH and free $\mathrm{T} 4$ were $0.06 \mathrm{mIU} / \mathrm{L}$ and $0.05 \mathrm{ng} / \mathrm{dL}$, respectively.

Since TSH levels decrease physiologically during pregnancy, we categorized them following the American Thyroid Association (ATA) criteria [16], which consider a normal range of $0.1-4 \mathrm{mIU} / \mathrm{L}$ for pregnant women, and concentrations $>4 \mathrm{mlU} / \mathrm{L}$ to be suggestive of hypothyroidism.

Hypothyroxinemia was defined as a free T4 lower than $0.76 \mathrm{ng} / \mathrm{dL}$. So, isolated hypothyroxinemia was defined as TSH concentrations $\leq 4 \mathrm{mlU} / \mathrm{L}$ and a free T4 concentration $<0.76 \mathrm{ng} / \mathrm{dL}$. Subclinical hypothyroidism was defined as TSH concentrations $>4 \mathrm{mlU} / \mathrm{L}$, and a free T4 concentration $\geq 0.76 \mathrm{ng} / \mathrm{dL}$. Overt hypothyroidism was considered if $\mathrm{TSH}$ concentrations $>4 \mathrm{mlU} / \mathrm{L}$ and free $\mathrm{T} 4$ concentration $<0.76 \mathrm{ng} / \mathrm{dL}$. Only three participants had subclinical hypothyroidism and seven had overt hypothyroidism. Therefore, we decided to create a variable with two categories: "Women with hypothyroxinemia"which included women with isolated hypothyroxinemia, women with subclinical hypothyroidism and women with overt hypothyroidism - and "Women without hypothyroxinemia".

\section{Pesticide exposure}

Due to financial reasons, we did not measure OP exposure biomarkers in all women; instead, we decided to use the partner's occupation as a proxy for pesticide exposure, including OP. A recent review of non-occupational pathways for pesticide exposure in women living in agricultural areas found that farm homes (where one or more family members use or contact pesticides at work) had higher concentrations of pesticides in residential dust than non-farm homes, whereas the results from biomonitoring studies were often difficult to interpret because of low detection rates or limited variability in pesticide biomarkers [17]. Previously, we found that workers frequently take the pesticide spraying equipment home, store pesticides and bring work shoes and clothes into the house, providing an important source of para-occupational exposure for their families [18]. Those women who reported that their husband worked in agricultural activities or transported or sold pesticides were considered para-occupationally exposed to them, while those whose partners' occupations did not involve exposure to these products were considered "not para-occupationally exposed". We implicitly assumed that para-occupationally exposed women would be more exposed to pesticides than not para-occupationally exposed women. Only two women were occupationally exposed to pesticides, as were their partners, so they were classified as "para-occupationally exposed".

To verify the previous assumption, we selected a random subsample of 65 women ( 20 of them were classified as para-occupationally and 45 as no para-occupationally exposed to OP by questionnaire), and we measured the urinary six common dialkylphosphate (DAP) metabolites of organophosphate pesticides: dimethylphosphate (DMP), dimethylthiophosphate (DMTP), dimethyldiithiophosphate (DMDTP), diethylphosphate (DEP), diethylthiophosphate (DETP), and diethyldithiophosphate (DEDTP). Metabolites were determined by gasliquid chromatography with Electron Capture Detector (GC-ECD). These metabolites are non-specific to a particular organophosphate but they are useful to estimate exposure to several organophosphates [19]. The dimethyl (DMP, DMTP, and DMDTP) and diethyl (DEP, DETP, and DEDTP) metabolite concentrations were converted to their molar concentrations $(\mu \mathrm{mol} / \mathrm{l})$ and summed to produce total DAP concentration for each sample. Metabolite concentrations were adjusted using creatinine concentration to correct for variable urine dilutions. Urinary creatinine concentration was determined by spectrophotometry using a commercial kit (Randox Creatinine Kit).

\section{Determining PON1 192QR, 55LM and -108CT polymorphisms}

Genomic DNA was isolated from peripheral blood using commercial kits + (Promega). DNA was quantified using a spectrophotometer at a $260 / 280 \mathrm{~nm}$ wavelength. Extraction purity was measured. Genotypes were 
determined using the TaqMan ${ }^{\circ}$ PCR assay (Applied Biosystems). When the specific fluorogenic probes of each allele are hybridized to the template during PCR, Taq polymerase is able to discriminate alleles. Excision results in a higher emission of a coloring agent. Each assay requires two unmarked PCR primers and two allele-specific probes. Each probe is marked with a coloring agent for identification (VIC and FAM). TaqMan real time PCR was used to detect polymorphism sites $-108 \mathrm{C} / \mathrm{T}$ (rs: 705379), 192Q/R (RS: 662), and 55 L/M (rs: 854560) in an automatic sequencing machine (ABI Prism 7000) according to the manufacturer's directions (Applied Biosystems, Foster City, CA, USA.). Discrimination was used for each studied genotype and allele, both manually and automatically, using an allelic discrimination software (7300 Sistema SDS Software ${ }^{\bullet}$ by Applied Biosystems).

To evaluate the precision and fidelity of the test, we reviewed the results at two different time point's moments by the same molecular biologist and also evaluated the results through intra-observer and between inter-observer.

\section{Description of covariates}

As potential confounders, variables considered relevant due to biological reasons or reported to be associated with the outcome were evaluated [20]: maternal age (years); gestational age (weeks) and body mass index (BMI) $[\mathrm{kg} /$ $\mathrm{m}^{2}$ ] at the time of the first interview, all of them were analyzed as continuous variables in regression models; other evaluated variables were: maternal education (categorized as elementary school, middle school and more than middle school), consumption of one or more cups of coffee per day during the pregnancy (Yes or No), active smoking and alcohol intake at some time during the individual's life, including the current pregnancy (Yes or No), consumption of iodine supplements from the 3 months before pregnancy to the date of the interview (Yes or No). Because a circadian and circannual variation in $\mathrm{TH}$ concentration has been reported [21,22], we also included the time of the day (in hours) and season of the sample-taking. We operationalized the "season" variable in a dichotomous manner, according to changes in Mexican summer time (April to September) and winter time (October to March).

\section{Statistical analysis}

TSH and free T4 concentrations were described using means and percentiles. Both $\mathrm{TH}$ were not normally distributed, and thus the geometric means were calculated. Allelic and genotype frequencies were calculated by direct counting. The $x^{2}$ test was used to determine genotype frequency deviation from Hardy-Weinberg (H-W) equilibrium expectations and to evaluate the significance of the linkage disequilibrium between the polymorphisms.
Women with or without hypothyroxinemia were compared by selected characteristics. In the case of categorical variables we used the $\chi^{2}$ test, while Student's t test or non-parametric tests (Mann-Whitney test) were used for continuous variables.

Total DAP concentrations available for 65 randomly selected women, were compared according to the para-occupational categories, by means of the non-parametric Mann-Whitney test.

The association of para-occupational exposure and each studied polymorphism, with hypothyroxinemia, was assessed by simple and multiple logistic regression models. PON1 genotypes were examined categorically and the wild genotype (PON1192QQ, PON155LL, PON1-108CC) of each one was considered as the reference. All final models were adjusted by maternal age, gestational age and BMI. We also kept those variables that modified the association between the independent variables of interest and hypothyroxinemia by more than 10\% (maternal education and coffee intake).

To assess potential interactions between para-occupational pesticide exposure and PON1 polymorphisms, interaction terms were included in multivariate models. Interaction was considered significant if $p$ value was $<0.15$.

Two sensitivity analyses were performed, one excluding the ten women with overt or subclinical hypothyroidism and another one excluding the two women occupationally exposed. We also carried out a sub- analysis evaluating the association between total DAP exposure and hypothyroxinemia in the subsample of 65 women with urine biomarkers.

Statistical analysis was performed with Stata 14.0 statistical software.

\section{Results}

In the whole group, 162 women (42.52\%) were classified as para-occupationally exposed to pesticides. In the subsample of women with available DAP information $(n=65)$, no significant difference was observed in the median of total urinary DAP concentration between those para-occupationally exposed $(n=20)$ and those no para-occupationally exposed $(n=45): 1.16$ vs. $0.83 \mu \mathrm{mol} / \mathrm{gr}$ creatinine, $p=0.56$. (Data not shown in Tables).

A total of 207 women (54\%) had free T4 concentrations lower than $0.76 \mathrm{ng} / \mathrm{dL}$ and 10 women had TSH $>4$ $\mathrm{mUI} / \mathrm{L}$. Out of these women, 197 had isolated hypothyroxinemia, three had subclinical hypothyroidism and seven had overt hypothyroidism (Table 1). As expected, TSH concentrations in women with hypothyroxinemia were significantly higher than in women without hypothyroxinemia $(1.40 \pm 1.50$ vs. $1.04 \pm 0.97 \mathrm{mIU} / \mathrm{L}, p$ $<0.01$ ) (Data not shown in tables). 
Table 1 Maternal thyroid hormone levels during the first 16 weeks of pregnancy

\begin{tabular}{|c|c|c|c|c|c|c|}
\hline Hormone & $n=381$ & (\%) & Mean $\pm S D^{a}$ & $\mathrm{P}_{10}{ }^{\mathrm{c}}$ & $\mathrm{P}_{50}{ }^{\mathrm{c}}$ & $P_{90}{ }^{c}$ \\
\hline Free $T 4(n g / d L)^{b}$ & & & $0.79 \pm 0.34$ & 0.48 & 0.75 & 0.96 \\
\hline$<0.76$ & 207 & 54.3 & & & & \\
\hline$\geq 0.76$ & 174 & 45.7 & & & & \\
\hline $\mathrm{TSH}(\mathrm{mUI} / \mathrm{L})^{\mathrm{b}}$ & & & $1.24 \pm 1.30$ & 0.22 & 0.87 & 2.58 \\
\hline$\leq 4$ & 371 & 97.4 & & & & \\
\hline$>4$ & 10 & 2.6 & & & & \\
\hline Overt hypothyroidism $^{d}$ & 7 & 1.8 & & & & \\
\hline Sub-Clinical hypothyroidism ${ }^{d}$ & 3 & 0.8 & & & & \\
\hline Isolated Hypothyroxinemia ${ }^{d}$ & 197 & 51.71 & & & & \\
\hline Without Hypothyroxinemia $^{e}$ & 174 & 45.67 & & & & \\
\hline
\end{tabular}

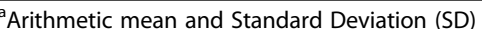

${ }^{\mathrm{b}}$ Geometric mean and SD: TSH $=0.83 \pm 0.8 \mathrm{mUl} / \mathrm{L} ;$ Free T4 $=0.75 \pm 0.3 \mathrm{ng} / \mathrm{dL}$

c 10,50 and 90 percentiles

${ }^{\mathrm{d}}$ Hypothyroxinemia includes: Overt hypothyroidism (TSH concentrations $>4 \mathrm{mlU} / \mathrm{L}$ and a free T4 concentration $<0.76 \mathrm{ng} / \mathrm{dL}$ ); Subclinical hypothyroidism (TSH concentrations $>4 \mathrm{mlU} / \mathrm{L}$, and a free $\mathrm{T} 4$ concentration $\geq 0.76 \mathrm{ng} / \mathrm{dL}$ ); Isolated hypothyroxinemia (TSH concentrations $\leq 4 \mathrm{mlU} / \mathrm{L}$ and a free

T4 concentration $<0.76 \mathrm{ng} / \mathrm{dL}$ )

'Without hypothyroxinemia: a free $\mathrm{T} 4$ concentration $\geq 0.76 \mathrm{ng} / \mathrm{dL}$ )

Women with hypothyroxinemia were older $(24.83 \pm$ 5.98 vs. $23.45 \pm 5.26 ; p=0.02$ ), had a higher frequency of elementary school education $(25.6 \%$ vs. $13.2 \% ; p=0.001)$ and less history of tobacco use $(27.5 \%$ vs. $37.93 \% ; p=0.03)$ than women without hypothyroxinemia. A higher frequency of blood samples obtained from women that were classified as hypothyroxinemic were taken in summer $(52.17 \%$ vs $41.95 \% ; p=0.05)$. No other significant differences were observed (Table 2).

None of the three studied polymorphisms was found to be in Hardy Weinberg equilibrium; no linkage disequilibrium was observed among the three polymorphisms. Genotype and allele distribution of polymorphisms by hypothyroxinemia status was significantly different in the case of polymorphism PON155LM. Allele M (42.41 vs. $26.69 \% ; p<0.01)$ and MM genotype (29.95 vs. $12.07 ; p<0.01)$ were more frequent in pregnant women with hypothyroxinemia than in those without hypothyroxinemia. After adjusting for maternal age, gestational age, maternal education, BMI and coffee intake during pregnancy, pesticide para-occupational exposure was not significantly associated with hypothyroxinemia (OR: $1.21 \quad 95 \%$ CI $\quad 0.75-1.94$ ). Hypothyroxinemia during the first half of pregnancy was three times more frequent among carriers of PON155MM genotype (OR $M M$ vs $L L: 3.03,95 \%$ CI $1.62,5.7)$, whereas women with genotypes PON1192RR (OR $R R$ vs QQ: 1.72, 95\%CI 0.93, 3.17) and PON1-108TT (OR TT vs CC: 1.60 , 95\% CI 0.90, 2.74) had a marginally higher likelihood of hypothyroxinemia than women with their respective wild genotypes (Table 3 ). Independently of para-occupational exposure and maternal genotypes, we also observed a significant decrease in the odds of hypothyroxinemia among those women who reported a higher educational level (OR $\geq$ high school vs elementary school: $0.28 ; 95 \%$ CI 0.14-0.59; OR middle school vs elementary school: 0.51 ; 95\% CI $0.28-0.97 ; p$ for trend $=0.001$ ) (Data not shown in tables).

Although we did not observe significant interactions between pesticide para-occupational exposure during pregnancy and the genetic polymorphisms, among women para-occupationally exposed, carriers of PON1$108 T T$ genotype, the odds of hypothyroxinemia were more than two times greater than those observed among carriers of $-108 C C$ genotype (Table 4). Similar results were observed when we included all polymorphisms in the model (Data not shown in tables).

These results did not change when we excluded the 10 women with overt and subclinical hypothyroidism or the two occupationally exposed women (data not shown). Likewise, regarding hypothyroxinemia and pesticides exposure, no association ( $\mathrm{OR}=1.00,95 \%$ CI $0.99-1.004)$ was observed in the subsampled women when we used as exposure biomarker, the urinary total DAP concentrations. (Data not shown in tables).

\section{Discussion}

The results of this study do not point to an association between para-occupational exposure to pesticides and maternal hypothyroxinemia in the first half of pregnancy. However, PON155MM genotype increased the frequency of hypothyroxinemia, independently of para-occupational exposure. Para-occupational exposure seems to be related to hypothyroxinemia, among women carriers of PON1$108 \mathrm{~T}$ allele, but the interaction between genotype and exposure was not statistically significant. 
Table 2 Selected characteristics of pregnant women according to hypothyroxinemia condition

\begin{tabular}{|c|c|c|c|c|}
\hline \multirow[t]{2}{*}{ Characteristics } & \multirow{2}{*}{$\begin{array}{l}\text { All women } \\
N=381\end{array}$} & \multicolumn{2}{|c|}{ Hypothyroxinemia } & \multirow[t]{2}{*}{$p$ value } \\
\hline & & $\begin{array}{l}\text { Yes } \\
n=207\end{array}$ & $\begin{array}{l}\text { No } \\
n=174\end{array}$ & \\
\hline \multicolumn{5}{|l|}{ Maternal Age (years) } \\
\hline Mean \pm SD & $24.20 \pm 5.7$ & $24.83 \pm 5.98$ & $23.45 \pm 5.26$ & 0.02 \\
\hline \multicolumn{5}{|l|}{ Marital status n(\%) } \\
\hline United $^{\mathrm{b}}$ & $338(88.71)$ & $188(90.82)$ & $150(86.21)$ & 0.16 \\
\hline No united & $43(11.29)$ & $19(9.18)$ & $24(13.79)$ & \\
\hline \multicolumn{5}{|l|}{ Education n(\%) } \\
\hline Elementary school & 76 (19.95) & $53(25.60)$ & $23(13.22)$ & $<0.01$ \\
\hline Middle school & $189(49.61)$ & $105(50.72)$ & $84(48.28)$ & \\
\hline$>$ Middle school & $116(30.45)$ & $49(23.67)$ & $67(38.51)$ & \\
\hline \multicolumn{5}{|l|}{ Gestational age (weeks) } \\
\hline Mean \pm SD & $10.20(2.80)$ & $10.36 \pm 2.83$ & $9.99 \pm 2.74$ & 0.20 \\
\hline \multicolumn{5}{|l|}{ Body Mass Index ${ }^{c}$} \\
\hline Mean \pm SD & $24.50(4.40)$ & $24.85 \pm 4.46$ & $24.07 \pm 4.30$ & 0.08 \\
\hline \multicolumn{5}{|l|}{ Coffee intake n(\%) } \\
\hline Yes & $293(76.90)$ & $153(73.91)$ & $140(80.86)$ & 0.13 \\
\hline No & $88(23.10)$ & $54(26.09)$ & $34(19.54$ & \\
\hline \multicolumn{5}{|l|}{ Parity n(\%) } \\
\hline Primiparous & $157(41.21)$ & 79 (38.16) & $78(44.83)$ & 0.19 \\
\hline Multiparous & $224(58.79)$ & $128(61.84)$ & $96(55.17)$ & \\
\hline \multicolumn{5}{|l|}{ Smoking n(\%) } \\
\hline Yes & $123(32.28)$ & $57(27.54)$ & $66(37.93)$ & 0.03 \\
\hline No & $258(67.72)$ & $150(72.46)$ & $108(62.07)$ & \\
\hline \multicolumn{5}{|l|}{ Alcohol intake n(\%) } \\
\hline Yes & $253(66.40)$ & $137(66.18)$ & $116(66.67)$ & 0.92 \\
\hline No & $128(33.60)$ & $70(33.82)$ & $58(33.33)$ & \\
\hline \multicolumn{5}{|c|}{ lodine supplementation ${ }^{d} \mathrm{n}(\%)$} \\
\hline Yes & $43(11.91)$ & $24(12.18)$ & 19 (11.59) & 0.86 \\
\hline No & $318(88.09)$ & $173(87.82)$ & $145(88.41)$ & \\
\hline \multicolumn{5}{|l|}{ Sampling season n(\%) } \\
\hline Summer & $181(47.51)$ & $108(52.17)$ & $73(41.95)$ & 0.05 \\
\hline Winter & $200(52.49)$ & $99(47.83)$ & $101(58.05)$ & \\
\hline
\end{tabular}

${ }^{a} \mathrm{X}^{2}$ or Student t-test, except for BMI, where Mann Whitney test was used

bUnited includes married and women in free union

cAt time of interview

${ }^{d}$ From 3 months before pregnancy until time of interview

Biological mechanisms that might explain the independent association between PON1 polymorphisms and hypothyroxinemia are not clear, but a possible hypothesis is through the antioxidant ability of PON1 [13]. Both PON1 polymorphisms and thyroid function have been independently related to oxidative stress [23, 24]. PON1 is an antioxidant enzyme that prevents the peroxidation of LDL and in myocardial infarct patients, a negative association was observed between PON1 concentrations and malonyl aldehyde (MDA) concentrations, an oxidative stress marker [23]. Moreover, polymorphism $192 Q / R$ has been associated with a higher frequency of coronary spasm and higher plasmatic concentrations of another oxidative stress marker, thiobarbituric acid-reactive substances (TBARS) [25]. In psoriasis patients, whose pathogenesis has also been linked to oxidative stress, it was also found that PON155M allele carriers have significantly higher MDA concentrations than PON155L allele carriers [26].

An adequate equilibrium between oxidation products and antioxidant enzymes is necessary for correct thyroid function. Alterations in this balance can be due to an increase in oxidant production or a decreased quality or concentration of antioxidant enzymes [13]. Physiologically, pregnancy increases oxygen demand and, consequently, Reactive Oxygen Species (ROS) production, as well as lipid peroxidation [27]. ROS and free radicals can have both beneficial and detrimental effects on the thyroid gland. Thus, although hydrogen peroxide is essential to thyroid hormone production, as it is a co-factor for iodization of T4 precursors, ROS increase can cause thyroid dysfunction $[28,29]$. In patients with kidney insufficiency who were not undergoing dialysis, it was found that MDA increase was associated with a T3 and T4 decrease [30]. Similarly, fever has been associated with increased production of oxidative stress markers, such as TBARS and MDA, and with decreased 5-monoiodinase activity, which in turn decreases T3-to-T4 conversion [31]. It has also been observed that oxidative stress inhibits transcription factors bonding to thyroid differentiation genes [32]. Since pregnancy is a pro-oxidant state, reduced PON1 activity or concentration associated with some PON1 polymorphisms could alter this equilibrium between oxidation products and antioxidant enzymes, affecting thyroid function.

Genotype and allele distributions of polymorphisms PON1192QR and PON155LM are consistent with the results found in a racially mixed population in Mexico, where alleles $P O N 1192 Q$ and $P O N 155 L$ were the most frequent (52.2 and $84.6 \%$, respectively) [33]. In our study population none of the three studied polymorphisms was found to be in Hardy Weinberg equilibrium; this could be due to the fact that the inhabitants are in closed villages, with a small number of inhabitants and in which it is common to find that marriages occur among the inhabitants of the same community, which would limit genetic diversity. TSH concentration was significantly higher in women with hypothyroxinemia, compared to women without hypothyroxinemia, which is consistent with the physiological feedback response of the hypothalamus-hypophysis-thyroid axis.

It is difficult to compare our results to those of other researchers, because few epidemiological studies have 
Table 3 Association of para-occupational exposure to pesticides during pregnancy and PON1 genotypes with maternal hypothyroxinemia

\begin{tabular}{|c|c|c|c|c|c|c|}
\hline \multirow[t]{2}{*}{ Characteristics } & \multirow{2}{*}{$\begin{array}{l}\text { All women } \\
n=381(\%)\end{array}$} & \multicolumn{4}{|c|}{ Hypothyroxinemia } & \multirow[t]{2}{*}{$p$ for trend } \\
\hline & & $\begin{array}{l}\text { Yes } \\
n=207(\%)\end{array}$ & $\begin{array}{l}\text { No } \\
n=174(\%)\end{array}$ & Crude OR $(95 \% \mathrm{Cl})$ & Adjusted OR $(95 \% \mathrm{Cl})$ & \\
\hline \multicolumn{7}{|c|}{ Para-occupational exposure to pesticides during pregnancy ${ }^{\mathrm{a}}$} \\
\hline No & $219(57.48)$ & $113(54.59)$ & $106(60.92)$ & 1.0 & 1.0 & \\
\hline Yes & $162(42.52)$ & $94(45.41)$ & $68(39.08)$ & $1.35(0.88-2.06)$ & $1.21(0.75-1.94)$ & \\
\hline \multicolumn{7}{|l|}{ PON1 192QR } \\
\hline QQ & $119(31.23)$ & $62(29.95)$ & $57(32.76)$ & 1.0 & 1.0 & 0.11 \\
\hline QR & $161(42.26)$ & $82(39.61)$ & $79(45.40)$ & $0.89(0.54-1.45)$ & $0.87(0.52-1.47)$ & \\
\hline $\mathrm{RR}$ & $101(26.51)$ & $63(30.43)$ & $38(21.84)$ & $1.68(0.95-2.96)$ & $1.66(0.92-2.99)$ & \\
\hline Q allele & 399 (52.30) & 206 (49.75) & $193(55.39)$ & 1 & & \\
\hline $\mathrm{R}$ allele & $363(47.55)$ & $208(50.12)$ & $155(44.48)$ & $1.31(0.98-1.77)$ & $1.30(0.96-1.77)$ & \\
\hline \multicolumn{7}{|l|}{ PON155LM*b } \\
\hline LL & $195(51.18)$ & $93(44.93)$ & $102(58.62)$ & 1.0 & 1 & 0.001 \\
\hline LM & $103(27.03)$ & $52(25.12)$ & $51(29.31)$ & $0.95(0.58-1.55)$ & $1.10(0.65-1.84)$ & \\
\hline MM & $83(21.78)$ & $62(29.95)$ & $21(12.07)$ & $2.47(1.37-4.45)$ & $3.01(1.63-5.57)$ & \\
\hline $\mathrm{L}$ allele & $493(64.58)$ & $238(57.35)$ & $255(73.18)$ & 1 & 1 & \\
\hline M allele & $269(35.23)$ & $176(42.41)$ & $93(26.69)$ & $1.67(1.21-2.29)$ & $1.93(1.38-2.69)$ & \\
\hline \multicolumn{7}{|l|}{ PON1-108CT*b } \\
\hline $\mathrm{CC}$ & $130(34.12)$ & $61(29.47)$ & $69(39.66)$ & 1.0 & 1 & 0.21 \\
\hline $\mathrm{CT}$ & $140(36.75)$ & $83(40.10)$ & 57 (32.76) & $1.36(0.82-2.24)$ & $1.36(0.81-2.31)$ & \\
\hline$\pi$ & $111(29.13)$ & $63(30.43)$ & $48(27.59)$ & $1.38(0.81-2.35)$ & $1.42(0.82-2.44)$ & \\
\hline C allele & $400(52.48)$ & $205(49.40)$ & $195(55.96)$ & 1 & 1 & \\
\hline T allele & $362(47.42)$ & $209(50.36)$ & $153(43.91)$ & $1.23(0.92-1.66)$ & $1.25(0.92-1.70)$ & \\
\hline
\end{tabular}

${ }^{a}$ Model adjusted by: maternal age, education, gestational age, coffee intake, body mass index and maternal PON 1 Genotypes

${ }^{b}$ Model adjusted by: maternal age, education, gestational age, coffee intake, body mass index and para-occupational exposure to pesticides during pregnancy

${ }^{*} \mathrm{D}$ ' between PON155LM and PON1-108CT polymorphisms $p=0.82$; Hardy-Weinberg equilibrium for all polymorphisms: $p<0.05$

explored the effects of pesticide exposure on the thyroid profile of pregnant women. Most of them have evaluated the effect of persistent organochlorine compounds, founding inconsistent results [14]. Zhang et al., in Japan, found no association between urinary pyrethroid concentrations and maternal thyroid profile during the first trimester of pregnancy [34], nor with the infant's thyroid profile at birth [35]; however, these results have been questioned due to possible selection bias [4]. A cohort study performed in Denmark on women who worked in greenhouses during pregnancy and were classified as moderately/highly exposed or not exposed to pesticides (in general), found a negative association between prenatal exposure to these compounds and the TSH concentrations of their children $6-11$ years of age $(\beta=-0.56,95 \% \mathrm{CI}$ $-1.287,-0.022)$, but the effect upon maternal thyroid function during pregnancy was not evaluated [36].

In a previous study performed on male flower workers from the geographical area of the present study, we found a significant interaction between DAP concentrations and polymorphism PON1192QR, upon serum TSH levels, and to a lesser extent, upon T3 levels. No interaction was observed with polymorphism PON155LM [8]. Nonetheless, comparability between studies is limited, given that our population includes pregnant women who are mainly para-occupationally exposed to pesticides and exposure biomarkers were not available. We only found a single previous study, performed on healthy post-menopausal women not exposed to pesticides, that assessed the effect of $P O N 1192 Q R$ polymorphism on the thyroid profile finding that $R$ allele carriers had significantly lower free $\mathrm{T} 3$ concentrations than women with $Q Q$ genotype (homozygous QQ: $2.46 \mathrm{pg} / \mathrm{ml}$, heterozygous $2.05 \mathrm{pg} / \mathrm{ml}$, homozygous $R R: 2.16 \mathrm{pg} / \mathrm{ml} ; p=0.047$ ) [13].

For the correct interpretation of our results, we must take into account some limitations: We cannot reject a potential misclassification error because we assumed that pregnant women, whose partners worked in a job involving pesticide use, would be more exposed to OP and other pesticides than women with partners who held a different type of job. However, all women resided in localities where floriculture is one of the main economic 
Table 4 Models results for the interaction between para-occupational pesticide exposure during pregnancy and PON1 genotypes on maternal hypoythyroxinemia

\begin{tabular}{|c|c|c|c|c|c|c|}
\hline \multirow{3}{*}{$\begin{array}{l}\text { Maternal } \\
\text { PON } 1 \text { Genotype }\end{array}$} & \multirow[b]{3}{*}{$n$} & \multicolumn{5}{|c|}{ Para-occupational exposure during pregnancy } \\
\hline & & \multicolumn{2}{|l|}{ Yes } & \multicolumn{3}{|l|}{ No } \\
\hline & & Crude OR (95\% Cl) & Adjusted OR $(95 \% \mathrm{Cl})$ & $\mathrm{n}$ & Crude OR (95\% CI) & Adjusted $\mathrm{OR}^{\mathrm{a}}(95 \% \mathrm{Cl})$ \\
\hline \multicolumn{7}{|l|}{ PON1192 } \\
\hline QQ & 55 & $1.10(0.52-2.34)$ & $0.97(0.44-2.15)$ & 64 & 1.0 & 1.0 \\
\hline$Q R$ & 66 & $1.27(0.47-3.43)$ & $1.28(0.45-3.62)$ & 95 & $0.81(0.42-1.56)$ & $0.78(0.75-1.94)$ \\
\hline $\mathrm{RR}$ & 41 & $1.61(0.50-5.14)$ & $1.52(0.46-5.04)$ & 60 & $1.41(0.67-2.96)$ & $1.39(0.64-3.0)$ \\
\hline \multicolumn{7}{|c|}{$p$ for interaction: 0.78} \\
\hline \multicolumn{7}{|l|}{ PON155 } \\
\hline LL & 82 & $1.13(0.63-2.04)$ & $1.07(0.58-1.99)$ & 113 & 1.0 & $0.94-1.091 .0$ \\
\hline LM & 45 & $1.31(0.48-3.56)$ & $1.15(0.41-3.25)$ & 58 & $0.84(0.44-1.62)$ & $1.02(0.51-2.05)$ \\
\hline MM & 35 & $1.87(0.55-6.38)$ & $1.49(0.42-5.27)$ & 48 & $1.96(0.94-4.09)$ & $2.59(1.21-5.57)$ \\
\hline \multicolumn{7}{|c|}{$p$ for interaction: 0.82} \\
\hline \multicolumn{7}{|l|}{ PON1108 } \\
\hline $\mathrm{CC}$ & 54 & $0.85(0.41-1.76)$ & $0.70(0.32-1.49)$ & 76 & 1 & 1.0 \\
\hline CT & 62 & $1.98(0.72-5.48)$ & $2.11(0.73-6.10)$ & 78 & $1.00(0.52-1.95)$ & $0.98(0.48-1.49)$ \\
\hline$\pi$ & 46 & $2.11(0.71-6.33)$ & $2.49(0.79-7.81)$ & 65 & $1.02(0.51-2.04)$ & $0.96(0.47-1.98)$ \\
\hline \multicolumn{7}{|c|}{$p$ for interaction: 0.23} \\
\hline
\end{tabular}

${ }^{a}$ Models were adjusted by: maternal age, gestational age, maternal education, coffee intake, and body mass index

activities and OP are one of the most used pesticides; thus, it is possible that exposure levels of para-occupationally exposed women are quite similar to those of the rest of the study population. Nonetheless the possibility that our results could be a consequence of a differential measurement error is low, because exposure data were obtained from all women before $\mathrm{TH}$ determination, and whoever performed the thyroid hormone determination was unaware of the women's exposure status. A possible non-differential measurement error along with a low variability in exposure levels among our women could explain the lack of significant association between para-occupational exposure and hypothyroxinemia.

Additionally, we had no information on PON1 concentration and enzyme activity. This is relevant because even among individuals with the same genotype, PON1 activity can vary up to 13 times [37].

On the other hand, differences in the time and season of sampling as well as iodine bioavailability could affect $\mathrm{TH}$ concentrations. For these reasons, we adjusted by the time and season of sample-collection and by iodine supplementation but this did not confound the results of association between para-occupational exposure to pesticides or PON1 polymorphisms and hypothyroxinemia.

We found a high frequency of isolated hypothyroxinemia in our study population. According to a recent review, which included studies that measured the free T4 concentration by immunoassay, the prevalence of isolated hypothyroxinemia varied between 1.3 and $24 \%$ during pregnancy; the authors attribute this wide variation to the ethnic differences and iodine bioavailability of the studied populations, as well as to cut-off points selection [38]. The American Thyroid Association [16] has proposed that reference ranges for free $\mathrm{T} 4$ during pregnancy should be established for each specific population and trimester of pregnancy, in samples of women without thyroid disease, without thyroid antibodies and with adequate iodine consumption. Following these criteria, in Mexico, we only have found a study conducted in Yucatan [39] which established a reference range for the first trimester from 0.75 to $1.7 \mathrm{ng} / \mathrm{dL}$, not far from the range proposed by our laboratory ( 0.76 to $2.24 \mathrm{ng} / \mathrm{dL})$. A recent study including Mexican pregnant women without history of thyroid disease, reported that the prevalence of isolated hypothyroxinemia was $12.8 \%$; however, the whole frequency of thyroid disorders was $46.7 \%$ [40]; this suggests that prevalence of thyroid disorders during pregnancy in Mexico, could be greater than that reported by literature. Given that the prevalence of iodine deficiency is low in our study population [14], immunological factors and exposure to other endocrine disruptors as synthetic fertilizers that include nitrites in their composition, could explain the high frequency of isolated hypothyroxinemia we find, a hypothesis that should be evaluated in future studies. 


\section{Conclusion}

In these women living in areas where pesticides are routinely used, our findings suggest that PON1 55MM genotype is independently associated with maternal hypothyroxinemia during the first half of pregnancy. Since there is scarce literature on the subject, additional epidemiologic studies are required to confirm or refute our results. Basic research oriented towards elucidating the biological mechanisms through which PON1 polymorphisms could be involved in thyroid disruption in pro-oxidant conditions like pregnancy is also needed.

We found no association between hypothyroxinemia and para-occupational exposure, however we cannot claim that there is no correlation between hypothyroxinemia and OP pesticide exposure, because it is quite possible that the control group in this study is also highly exposed through other pathways.

\section{Abbreviations}

BMI: Body Mass Index; DAP: Dialkylphosphate metabolites; OP: Organophosphate pesticides; PCR: Polymerase Chain Reaction; PON1: Paroxonase 1; T4: Thyroxine; TSH: Thyroid-Stimulating Hormone

\section{Acknowledgements}

The authors thank the participants of this study. We also thank Carlos Jesús Sánchez and Eunice Elizabeth Félix-Arellano for their help in the revision of the English translation, and Alicia Blanco for their help in the references edition.

\section{Funding}

This study was funded by the National Council of Science and Technology of Mexico (CONACyT). Grant No. 180956

\section{Availability of data and materials}

The datasets generated and analyzed during this study are not publically available due to Ethics Committee of the Instituto Nacional de Salud Pública (National Institute of Public Health) of México restrictions. Non-identifiable data are however available from the authors upon reasonable request and with permission from the Ethics Committee at National Institute of Public Health, México.

\section{Declarations of interest}

none.

\section{Authors' contributions}

LTS drafted the paper. RG and CHG helped with genotyping. SBM and MPN helped with thyroid hormones determination. JIVP helped with statistical analysis. LYE and RMS helped with dyalkilphosphate (DAP) determination. JBM conceived and conducted the research. All authors read and approved the final manuscript.

\section{Competing interest}

The authors declare that there is no conflict of interest that could be perceived as prejudicing the impartiality of the reported research.

\section{Ethics approval and consent to participate}

This study was approved by the Ethics Committee of the National Public Health Institute of Mexico. All participating women signed an informed consent letter; for women under 18 years of age, in addition to their agreement we obtained an informed consent letter from their parents.

\section{Consent for publication}

Not Applicable.

\section{Publisher's Note}

Springer Nature remains neutral with regard to jurisdictional claims in published maps and institutional affiliations.

\section{Author details}

${ }^{1}$ Instituto Nacional de Salud Pública, Av. Universidad 655, Col. Sta. María Ahuacatitlán, 62100 Cuernavaca, Morelos, CP, Mexico. ${ }^{2}$ Physiology Department, Instituto Nacional de Cardiología Ignacio Chávez, Juan Badiano 1, 14080 Mexico City, C.P, Mexico. ${ }^{3}$ Faculty of Medicine, Universidad Autónoma de Coahuila, Morelos 900, 27000 Torreón, Coahuila, C.P, Mexico.

${ }^{4}$ Faculty of Medicine, Universidad Autónoma de San Luís Potosí, Venustiano Carranza 2405. San Luis Potosí, 78000 San Luís Potosí, C.P, Mexico.

Received: 22 November 2018 Accepted: 20 March 2019

Published online: 11 April 2019

\section{References}

1. Grau G, Aguayo A, Vela A, et al. Normal intellectual development in children born from women with hypothyroxinemia during their pregnancy. J Trace Elem Med Biol. 2015:31:18-24.

2. Modesto T, Tiemeier H, Peeters RP, et al. Maternal mild thyroid hormone insufficiency in early pregnancy and attention-deficit/hyperactivity disorder symptoms in children. JAMA Pediatr. 2015;169:838-45. https://doi.org/10. 1001/jamapediatrics.2015.0498.

3. Finken MJ, van Eijsden M, Loomans EM, et al. Maternal hypothyroxinemia in early pregnancy predicts reduced performance in reaction time tests in 5to 6-year-old offspring. J Clin Endocrinol Metab. 2013;98:1417-26. https:// doi.org/10.1210/jc.2012-3389.

4. Campos É, Freire C. Exposure to non-persistent pesticides and thyroid function: A systematic review of epidemiological evidence. Int J Hyg Environ Health. 2016;219:481-97. https://doi.org/10.1016/j.ijheh.2016.05.006.

5. Fortenberry GZ, Hu H, Turyk M, et al. Association between urinary 3, 5, 6trichloro-2-pyridinol, a metabolite of chlorpyrifos and chlorpyrifos-methyl, and serum T4 and TSH in NHANES 1999-2002. Sci Total Environ. 2012;424: 351-5. https://doi.org/10.1016/j.scitotenv.2012.02.039.

6. Lacasaña M, López-Flores I, Rodríguez-Barranco M, et al. Association between organophosphate pesticides exposure and thyroid hormones in floriculture workers. Toxicol Appl Pharmacol. 2010;243:19-26. https://doi.org/ 10.1016/j.taap.2009.11.008.

7. Meeker JD, Barr DB, Hauser R. Thyroid hormones in relation to urinary metabolites of non-persistent insecticides in men of reproductive age. Reprod Toxicol. 2006;22:437-42.

8. Lacasaña M, López-Flores I, Rodríguez-Barranco M, et al. Interaction between organophosphate pesticide exposure and PON1 activity on thyroid function. Toxicol Appl Pharmacol. 2010;249:16-24.

9. Mackness MI, Arrol S, Durrington PN. Paraoxonase prevents accumulation of lipoperoxides in low-density lipoprotein. FEBS Lett. 1991;286(1-2):152-4 Erratum in: FEBS Lett 1991 Nov 4:292(1-2):307.

10. Furlong CE, Cole TB, Jarvik GP, et al. Role of paraoxonase (PON1) status in pesticide sensitivity: genetic and temporal determinants. Neurotoxicology. 2005;26:651-9.

11. Aviram M, Hardak E, Vaya J, et al. Human serum paraoxonases (PON1) Q and $R$ selectively decrease lipid peroxides in human coronary and carotid atherosclerotic lesions: PON1 esterase and peroxidase-like activities. Circulation. 2000;101:2510-7.

12. Searles Nielsen S, Mueller BA, De Roos AJ, et al. Risk of brain tumors in children and susceptibility to organophosphorus insecticides: the potential role of paraoxonase (PON1). Environ Health Perspect. 2005;113:909-13.

13. Lambrinoudaki I, Kaparos G, Rizos D, et al. Apolipoprotein E and paraoxonase 1 polymorphisms are associated with lower serum thyroid hormones in postmenopausal women. Clin Endocrinol. 2009;71:284-90. https://doi.org/10.1111/j.1365-2265.2008.03476.x.

14. Hernández-Mariano JÁ, Torres-Sánchez L, Bassol-Mayagoitia S, et al. Effect of exposure to p,p'-DDE during the first half of pregnancy in the maternal thyroid profile of female residents in a Mexican floriculture area. Environ Res. 2017;156:597-604. https://doi.org/10.1016/j.envres.2017.04.013.

15. Schilmann A, Lacasaña M, Blanco-Muñoz J, et al. Identifying pesticide use patterns among flower growers to assess occupational exposure to mixtures. Occup Environ Med. 2010;67:323-9. https://doi.org/10.1136/oem. 2009.047175 . 
16. Alexander EK, Pearce EN, Brent GA, et al. Guidelines of the American Thyroid Association for the Diagnosis and Management of Thyroid Disease During Pregnancy and the Postpartum. Thyroid. 2017;27:315-89. https://doi.org/10. 1089/thy.2016.0457.

17. Deziel NC, Friesen MC, Hoppin JA, et al. A review of nonoccupational pathways for pesticide exposure in women living in agricultural areas. Environ Health Perspect. 2015;123:515-24. https://doi.org/10.1289/ehp.1408273.

18. Blanco-Muñoz J, Lacasaña M. Practices in pesticide handling and the use of personal protective equipment in Mexican agricultural workers. J Agromedicine. 2011;16:117-26. https://doi.org/10.1080/1059924X.2011.555282.

19. Eskenazi B, Harley K, Bradman A, et al. Association of in utero organophosphate pesticide exposure and fetal growth and length of gestation in a agricultural population. Environ Health Perspect. 2004;112: 1116-24.

20. Taylor RN, Lebovic DI. Endocrinología del embarazo. In: Martínez Moreno M, editor. Endocrinología básica y clínica. México: Manual Moderno; 2007. p. 671-92.

21. Russell W, Harrison RF, Smith N, et al. Free triiodothyronine has a distinct circadian rhythm that is delayed but parallels thyrotropin levels. J Clin Endocrinol Metab. 2008;93:2300-6.

22. Villagrán De Rosso EV, Elizondo CM, Posadas Martínez ML, et al. Efectos del fotoperíodo y la temperatura ambiental en los niveles plasmáticos de hormona estimulante de tiroides (TSH). Phothoperiod and environmental temperature effects on plasmatic levels of thyroid stimulating hormone (TSH), RAEM. 2013, 2013;50:163-9.

23. Ferré N, Marsillach J, Camps J, Mackness B, Mackness M, Riu F, Coll B, Tous $M$, Joven J. Paraoxonase-1 is associated with oxidative stress, fibrosis and FAS expression in chronic liver diseases. J Hepatol. 2006;45:51-9.

24. Karbownik M, Lewinski A. The role of oxidative stress in physiological and pathological processes in the thyroid gland; possible involvement in pinealthyroid interactions. Neuro Endocrinol Lett. 2003;24:293-303.

25. Ito T, Yasue H, Yoshimura M, et al. Paraoxonase gene Gln192Arg (Q192R) polymorphism is associated with coronary artery spasm. Hum Genet. 2002; 110:89-94

26. Asefi M, Vaisi-Raygani A, Bahrehmand F, et al. Paraoxonase 1 (PON1) 55 polymorphism, lipid profiles and psoriasis. Br J Dermatol. 2012;167:1279-86. https://doi.org/10.1111/j.1365-2133.2012.11170.x

27. Gitto E, Reiter RJ, Karbownik M, et al. Causes of oxidative stress in the preand postnatal period. Biol Neonate. 2002;81:146-57.

28. Joanta AE, Filip A, Clichici $S$, et al. lodide excess exerts oxidative stress in some target tissues of the thyroid hormones. Acta Physiol Hung. 2006;93: 347-59.

29. Serrano-Nascimento C, Salgueiro RB, Vitzel KF, et al. lodine excess exposure during pregnancy and lactation impairs maternal thyroid function in rats. Endocr Connect. 2017;6:510-21. https://doi.org/10.1530/EC-17-0106.

30. Singh PA, Bobby Z, Selvaraj N, et al. An evaluation of thyroid hormone status and oxidative stress in undialyzed chronic renal failure patients. Indian Journal of Physiology and Pharmacology. 2006:50:279-84.

31. Brzezińska-Slebodzińska E. Fever induced oxidative stress: the effect on thyroid status and the 5'-monodeiodinase activity, protective role of selenium and vitamin E. J Physiol Pharmacol. 2001;52:275-84.

32. Kambe F, Nomura $Y$, Okamoto $T$, et al. Redox regulation of thyroidtranscription factors, Pax- 8 and TTF-1, is involved in their increased DNAbinding activities by thyrotropin in rat thyroid FRTL-5 cells. Mol Endocrinol. 1996;10:801-12

33. Gamboa R, Zamora J, Rodríguez-Pérez JM, et al. Distribution of paraoxonase PON1 gene polymorphisms in Mexican populations. Its role in the lipid profile. Exp Mol Pathol. 2006;80:85-90.

34. Zhang J, Hisada A, Yoshinaga J, et al. Exposure to pyrethroids insecticides and serum levels of thyroid-related measures in pregnant women. Environ Res. 2013;127:16-21. https://doi.org/10.1016/j.envres.2013.10.001.

35. Zhang J, Yoshinaga J, Hisada A, et al. Prenatal pyrethroid insecticide exposure and thyroid hormone levels and birth sizes of neonates. Sci Total Environ. 2014;275(9):488-9. https://doi.org/10.1016/j.scitotenv.2014.04.104.

36. Wohlfahrt-Veje C, Main KM, Schmidt IM, et al. Lower birth weight and increased body fat at school age in children prenatally exposed to modern pesticides: a prospective study. Environ Health. 2011;10:79. https://doi.org/ 10.1186/1476-069X-10-79

37. Costa LG, Cole TB, Furlong CE. Polymorphisms of paraoxonase (PON1) and their significance in clinical toxicology of organophosphates. J Toxicol Clin Toxicol. 2003:41:37-45.
38. Dosiou C, Medici M. Isolated maternal hypothyroxinemia during pregnancy: knowns and unknowns. Eur J Endocrinol. 2017:176:R21-38.

39. Quinn FA, Reyes-Mendez MA, Nicholson L, et al. Thyroid function and thyroid autoimmunity in apparently healthy pregnant and non-pregnant Mexican women. Clin Chem Lab Med. 2014;52:1305-11.

40. Cruz-Cruz EA, Ramírez-Torres A, Pimentel-Nieto D, et al. Prevalence of clinical and subclinical hypothyroidism during pregnancy in a pregnant women population. Ginecol Obstet Mex. 2014;82:717-24.

\section{Ready to submit your research? Choose BMC and benefit from:}

- fast, convenient online submission

- thorough peer review by experienced researchers in your field

- rapid publication on acceptance

- support for research data, including large and complex data types

- gold Open Access which fosters wider collaboration and increased citations

- maximum visibility for your research: over $100 \mathrm{M}$ website views per year

At $\mathrm{BMC}$, research is always in progress.

Learn more biomedcentral.com/submissions 